\title{
Environmental Awareness, Environmental Attitude And Consumer Attitude- A Study Of Correlation In Variables
}

\author{
Jubilee Goyal $^{1^{*}}$, Dr. H.S. Grewal ${ }^{2}$ \\ ${ }^{1}$ Assistant Professor, Graphic Era University, Dehradun \\ ${ }^{2}$ Dr. H.S. Grewal- Director and Professor, Management, Doon Business School, Dehradun
}

\begin{abstract}
The current study was conducted to find the correlation between the variablesenvironmental awareness, environmental attitude and consumer attitude.The study was done on 600 respondents. The area of study was Dehradun, Haridwar and Roorkee, three cities in Uttarakhand, India. The objective of the study was to find the respondent's level of environmental awareness, to measure their level of environmental attitude and consumer attitude and to find out if a relationship existed between environmental awareness and environment attitude and its dimensions. Further the relationship between environmental awareness and consumer attitude was also found. Factorial design was used and levels of awareness were matched with levels of occupation and gender.Stratified random sampling, a probability sampling technique, was used to choose the sample.Environmental Awareness Test (EAWT) by Dr. K. Yeshodhara was used to assess the environmental awareness of the subjects. Taj Environmental Attitude Scale (TEAS) by Dr. Haseen Taj was used to measure the environmental attitude of the respondents and Consumer Attitude Scale (CAS) was designed by author to measure the consumer attitude of the respondents.

Correlation was calculated to analyse the data and to test the proposed hypothesis. The findings revealed a significant correlation among the variables.
\end{abstract}

Keywords:

Environmental awareness, Environmental attitude, Consumer attitude, Dehradun

Article Received: 18 October 2020, Revised: 3 November 2020, Accepted: 24 December 2020

\section{INTRODUCTION}

Knowing the deterioration in environment and growing environmental problems/issues in India, the significance of environmental awareness, its current state and changing levelsneed to be understood carefully. According to Hassan, Noordin and Sulaiman(2010), environmental awareness includes emotional, attitude and practice of sustainability awareness. In the study of Altin et al. (2014), environmental awareness is referred as awarenessto the environmental issues and active involvement in environmental organizations. Environmental awareness is a starting point, a trigger to nurture positive attitudes towards the environment which leads to positive environmental behaviour. Hence, the awareness and concern of environmental issues and the causes and adverse impacts are all necessary to be measured. The higher individual cognitive level to environmental issues and the cause-effect schemes, the higher the intentional environmental behaviour.
Allport (1935), defined attitude as a mental and neural state of readiness, which exerted a directing influence upon the individual's response to all objects and situations, with which it was related. According to Schultz and Zelezny (2000), attitude of environmental concern are rooted in a person's concept of self and the degree to which an individual perceives him or herself to be an integral part of the natural environment. Therefore environmental attitudes is characteristic of an individual's concern for the physical environment, worthy of protection, understanding and enhancement (Gifford, 2002).Similarly consumers are worried aboutthe impact of environmental damage on their health andsafety. Their anxiety hascompelled the marketers to incorporateenvironment issue in their decision making. Consumer attitude thus play a significance role. Consumer attitude towards concern for health and environmental consciousness, have emerged as main attractions for theconsumers towards organic food. Paladino 
and Baggiere( 2008), said that consumers should take some responsibility to reduce environmental damagethrough recycling and purchasing ecologically sound products. Fraj and Martinez (2007), suggested that the marketers should be aware of the importance of the attitude of the consumers of the ecologically high segment who were even prepared to switch

consumption and purchase other products for ecological reasons.

\section{METHODOLOGY}

\section{Objective:}

The objective of the present study was to find out the respondents level of environmental awareness, environment attitude and consumer attitude. Other objective was to determine a relationship between environmental awareness and environmental attitude and its dimensions. and also to find the relationship between environmental awareness and consumer attitude and its dimensions.

\section{Hypothesis:}

H1: Environmental awareness is positively

correlated to environmental attitude and its dimensions.

$\mathrm{H} 2$ : Environmental awareness is positively

correlated to consumer attitude and its dimensions.

\section{Sample:}

The study was done on 600 respondents in the city of Dehradun, Haridwar and Roorkee, in the state of Uttarakhand, India. Stratified random sampling technique was used. Sample consisted of equal number of professionals and non-professionals, further subdivided into males and females.

\section{Procedure:}

Firstly the respondents were given the Environmental Awareness Test (EAWT), to assess their level of environmental awareness. They were then asked to complete the questionnaire and a short break was given to them. This was followed by administering of Taj Environmental Attitude Scale (TEAS) and Consumer Attitude Scale (CAS).

The scoring of EAWT was done on the basis of the instructions given in the manual. On the basis of the scores, the respondents were categorized into three levels high, medium and low awareness. Similarly the scoring for environmental attitude test (TEAS), as discussed in the manual and scoring of consumer attitude scale (CAS) , as decided were executed. Data was then analyzed.

\section{Environmental Awareness Test (EAWT)}

Environmental Awareness Test (EAWT) was developed by K. Yeshodhara in 2003. This test is intended to measure the level of environmental awareness of the respondents. The test consists of 36 multi- choice items, which focused on eight different areas of environmental awareness

\section{Taj Environmental Attitude Scale (TEAS)}

Taj Environmental Attitude Scale (TEAS) was developed by Haseen Taj in 2001, following the Likert method of summated rating procedure. TEAS consisted of 61 items spread over six areas - attitude towards (1) Health and Hygiene (2) Wild life (3) Forests (4) Polluters (5) Population Explosion (6) Environment Concern

\section{Consumer Attitude Scale (CAS)}

Consumer attitude Scale (CAS) was developed by the author, following the Likert method of summated rating. CAS consisted of 20 questions to measure consumer attitude across four dimensions- attitude towards (1). Perception (2). Deterrents (3).Willingness to pay (4).Marketing efforts

The selected green products taken in the study are organic food products (organic pulses, organic spices, organic fruits and vegetables)

\section{RESULTS AND DISCUSSION}

To test the proposed hypothesis correlation were computed.

(Table 1) shows the correlation between environmental awareness and total environmental attitude and its dimensions and between environmental awareness and total consumer attitude and its dimensions.

Environmental awareness was found to be positively and highly correlated with total environmental attitude. Environmental awareness was also found to be positively and highly correlated to all the dimensions of environmental 
attitude health and hygiene, forests, polluters, population explosion and environment concern. This implies that respondents' environmental awareness about the environmental issues have a strong relation and positive impact on their environmental attitude and environmental friendly behaviour. Respondents' are aware that environment is rapidly deteriorating and their attitude towards environmental protection, environment concern and consciousness can save the planet earth. There environmental knowledge is reflected in their attitude towards recycling, participating in tree-planting, car pooling and need for sustainable behaviour.

Thereforeproposed $\mathrm{H} 1$ that environmental awareness is positively correlated to environmental attitude and its dimensions is accepted.

The findings of the current study are in line with previous studies.Ari \& Yilmaz (2017), revealed that students with certain level of environmental awareness had a positive attitude toward the environment. SimilarlyBozoglu et al. (2016), said that awareness of environmental issues had the highest influences on the respondent's environmental attitude and behaviour. Yumusak et al. (2016), also observed that participants' environmental awareness and environmental attitudes had been supporting each other. Martin \&Liem (2015), in their study found that environmental awareness, positively predicted pro environmental attitudes.

Environmentallyaware respondents have an understanding that food additives are hazardous to the health, pesticides should not be sprayed on vegetables and industrial and toxic waste should be dumped away from the residential areas. They have knowledge about several burning issues like the effects of acid rain on forests, need for higher participation in afforestation programmes, knowledge of issues such that government should not increase its revenue by clearing the forests and that cutting of forests is not essential to increase agricultural yield. Environmental awareness leads to information and beliefthat over population leads to poverty, family planning should be made mandatory to decrease population growth and population control assures reasonable standard of living for future generations.Thus environmental awareness significantly contributes in the development of environmental attitude, which may or may not manifest into sustainable behaviour.

Correlation was also studied between environmental awareness and consumer attitude (Table 1). Environmental awareness was found to be positively and significantly correlated to overall consumer attitude. Positive and significant correlation was also found between environmental awareness and all the dimensions of consumer attitude namely perception, deterrents, willingness to pay and marketing efforts. This implies that environmental awareness has a relationship and impact on the consumer attitude towards organic food products. Respondents are aware that organic food products are good for health and environment friendly. They are willing to pay premium prices for organic products as such products are good for them and for the environment. They are aware of the persisting environmental problems and issues but believe that many such products are marketing gags, with only a few genuine products.

ThusH2 is claimed that environmental awareness is positively correlated to consumer attitude and its dimensions.

The present findings are supported by past studies. Joshi and Rahman (2015), in their study concluded that knowledge of environmental issues positively influenced consumer intention, consumer attitudes and actual purchase of green products. Xie et al. (2015), also found that the main barriers to increasing the market share of organic food products were the consumers' lack of environmental knowledge. Mostafa (2007), reported that environmental knowledge and environmental concern were significant in forming attitude towards green products and green purchase.

Respondents with moderate and high level of environmental awareness believed in health benefits, taste and protection of environment. 
They prefer organic products because they are free from pesticides and chemical fertilizers. They choose organic products over conventional products because of their perception that organic foods are healthier, tastier and environmentally sound. They have higher willingness to pay considering the health and environment benefits of the product. Respondents also agree that such products are manufactured by big companies who make genuine claims about their authenticity. However they hold that organic food products are not easily available and are hard to identify. Thus environmental awareness has a positive and significant relationship with consumer attitude, which may or may not lead to green purchase.

Table 1: Correlations for Total Sample

\begin{tabular}{|c|c|c|c|c|c|c|c|c|c|c|c|c|}
\hline Var. & $\begin{array}{c}\text { EA } \\
\text { W }\end{array}$ & HH & FO & PO & $\mathbf{P E}$ & EC & Tot. & Per. & $\begin{array}{c}\text { Detr } \\
\text {. }\end{array}$ & $\begin{array}{c}\text { WT } \\
\mathbf{P}\end{array}$ & $\begin{array}{l}\text { M. } \\
\text { Eff. }\end{array}$ & Tot. \\
\hline $\begin{array}{c}\text { EA } \\
\text { W }\end{array}$ & 1.00 & 0.69 & 0.70 & 0.85 & 0.65 & 0.75 & 0.87 & 0.19 & 0.45 & 0.11 & 0.14 & 0.36 \\
\hline HH & & 1.00 & 0.76 & 0.79 & 0.63 & 0.67 & 0.83 & 0.08 & 0.00 & 0.14 & 0.15 & 0.31 \\
\hline FO & & & 1.00 & 0.80 & 0.64 & 0.73 & 0.85 & 0.13 & 0.01 & 0.16 & 0.13 & 0.34 \\
\hline PO & & --- & & 1.00 & 0.68 & 0.80 & 0.96 & 0.10 & 0.00 & 0.18 & 0.17 & $\mathbf{0 . 3 9}$ \\
\hline $\mathbf{P E}$ & & --- & & --- & 1.00 & 0.61 & 0.74 & 0.12 & 0.04 & 0.10 & 0.12 & 0.28 \\
\hline EC & & --- & & --- & --- & 1.00 & 0.87 & 0.16 & 0.00 & 0.15 & 0.15 & 0.37 \\
\hline Tot. & & --- & & --- & --- & --- & 1.00 & 0.13 & 0.02 & 0.16 & 0.16 & 0.40 \\
\hline Per. & & --- & & --- & --- & --- & --- & 1.00 & -0.05 & 0.11 & 0.05 & 0.43 \\
\hline $\begin{array}{c}\text { Detr } \\
\text {. }\end{array}$ & & --- & & --- & --- & --- & --- & --- & 1.00 & -0.03 & 0.04 & 0.24 \\
\hline $\begin{array}{c}\text { WT } \\
\text { P }\end{array}$ & & --- & & --- & --- & --- & --- & --- & --- & 1.00 & 0.22 & 0.53 \\
\hline $\begin{array}{c}\text { M.E } \\
\text { f }\end{array}$ & & --- & & --- & --- & --- & --- & --- & --- & --- & 1.00 & 0.54 \\
\hline Tot. & & --- & & --- & --- & --- & --- & --- & -- & --- & --- & 1.00 \\
\hline
\end{tabular}

\section{REFERENCES}

[1] Allport, G.W. (1935). Attitude. In Murchinson, Worcester and Massachusetts (Ed.). A Handbook of Social Psychology, 798-844: Clark University Press.

[2] Al Khasawneh, M. O. H. A. M. M. A. D. H. A. M. D. I., and Ahmed Shuhaiber. "A comprehensive model of factors influencing consumer attitude towards and acceptance of SMS advertising: an empirical investigation in Jordan." International Journal of Sales \& Marketing Management Research and Development 3.2 (2013): 1-22.
[3] Alsamydai, Mahmood Jasim, Husam Mustafa Alnaimi, and D. Dajani. "Using Fishbein model to measure individual's attitudes toward electronic communication means." International journal of sales and marketing management research and development 5.2 (2015): 1-18.

[4] Alsamydai, Mahmood Jasim, et al. "The factors influencing customer usage of mobile banking services in Jordan." International Journal of Business Management and Research 4.2 (2014): 6378. 
[5] Anja Kollmuss\& Julian Agyeman (2002),“ Mind the Gap: why do people act

[6] Environmentally and what are the barriers to pro-environmental behaviour?", Environmental Education Research, Vol. 8, No. 3.

[7] Ari, E.,\& Yilmaz, V.(2017),“ Effects of environmental illiteracy and environmental awareness among middle school students on environmental behaviour,"

Environment Development and Sustainability, 19(5), 1779-1793.

[8] Amoroso, D., and P. A. J. A. R. E. E. Ackaradejruangsri. "Exploring the adoption of mobile technologies in Thailand: Development of a research model." Journal of Business Management and Research 6.1 (2016): 19-28.

[9] Bozoglu et al. (2016), "Factors affecting the students' environmental awareness, attitudes and behaviors in OndokuzMayis University, Turkey," Fresenius Environmental Bulletin, Vol. 25, Issue 7, 2539-2553.

[10] Fraj, E. and Martinez, E. (2007), "Ecological consumer behaviour: an empirical analysis", International Journal of Consumer Studies, Vol. 31 No. 1, pp. 26-33.Haseen Taj: Manual for Environmental Attitude Scale, Agra, India, Nandini Enterprises, (2001).

[11] Joshi Y., Rahman. Z.(2015),"Factors Affecting Green Purchase Behaviour and Future Research Directions", International Strategic Management Review , Vol3, Issue 2, 128-143

[12] Martin, J. A. \&Liem D. G.(2015), “ The role of adaptability in tackling climate and environmental challenges ," Geographical Education Volume 28.

[13] Mostafa, M. M. (2007),“ A Hierarchical Analysis of the Green Consciousness of the Egyptian Consumer," Psychology and Marketing, 24(5): 445-473.

[14] Sharma, Deependra, and Harinder Pal. "Investigation about Consumer Attitude and its Antecedent towards Environmental Sustainable Apparel: A Case Study in Indian Context." International Journal of Environment, Ecology, Family and Urban Studies 9 (2019): 113-122.

[15] Xieet al.(2015), "Consumer perceptions and attitudes of organic food products in Eastern China,"British Food Journal ,117:3, 1105-1121 